\title{
Research on MOOCs Continuance
}

\author{
Bing Wu, Xiaohui Chen \\ School of Economics and Management, Tongji University,
}

\begin{abstract}
Keywords: MOOCs; Technology accept model (TAM); Task fit technology
Abstract This paper focuses on the major influencing factors about the use of the Massive Online Open Courses (MOOCs). It is promoted by the top universities domestic and overseas. Under the background of big data, MOOC develops rapidly, but its development is not smooth, especially the users' practical application. This paper adopts a integrated conceptual framework guided by the technology accept model (TAM) and task fit technology model (TTF) to explore factors that influence online participation among the users and to explain perceived effects of participation. Questionnaire survey was conducted online and offline and the data analyzed as descriptive statistics by multiple linear regression methods and structural equation modelling (SEM).Perceived social utility and learner's investigation significantly explained perceived effects on MOOCs. Also concluded that a range of factors shapes participation in MOOCs and initiatives such as students or office workers need regular, intensive consciousness to accept and use. The paper will put forward feasible and effective comments or suggestions to refine MOOCs platforms progressively.
\end{abstract}

\section{Introduction}

MOOC year is an indelible mark on the history of education, top universities at home and abroad have built multiple platforms to promote MOOC resources.

Massive Open Online Courses (MOOC) is based on the emerging form of online course curriculum and mobile smart technology. From 2003, the first 2300 MOOC registered users to millions nowadays, just a few years, MOOC has been developed from the silent to the blowout stage. With 2012 being called "MOOC first year", more and more world-class universities begin to join MOOC platform, solve shared problems such as unequal educational opportunities for quality education in some areas, then greatly expanded educational opportunities and promote educational equity. MOOC rapid development greatly exceeded the awareness rate and the depth perception. However, current research is mostly about MOOC analyze and explore literature from the perspective of technology, this paper will discuss MOOC development and its related issues from the user's point of view.

\section{Literature Review}

MOOCs evolution and composition. MOOCs evolution from OCW mainly refers to the concept of evolution MOOC education. MOOC is generally began from" Open Educational Resource" (ORE) movement, which is committed to providing free educational resources through the Internet ${ }^{[1]}$.

Kop and Sara think MOOC is composited by five major elements: teachers, learners, subjects, learning materials and situations (Kop, R, 2011; Sara Ibn El Ahrache etc., 2013) ${ }^{[2]}$. Li Qing (2012) ${ }^{[3]}$ observed and analyzed ten MOOC courses, summed up the general operating mode and extract the constituent elements of MOOC: the material elements (the platform and tools, course information, learning activities) and human element (curriculum teachers, learners, curriculum coordinator). Which can be seen from these studies, analysis on MOOC constituent elements have been included more "human" factor. Obviously, MOOC research starts from large-scale representation on a wide range, abundant resources, turned to a more substantive level, the nature of teaching and learning, as well as factors associated with teaching with "people" began to attract research-related scholars' attention.

Theoretical background and research model. Technology Acceptance Model (TAM) has been proposed after the verification of many scholars, the reliability and interpretation capabilities have been 
widely recognized, especially perceived usefulness and perceived ease of use of these two variables on system behavior wishes impact. On the basis of many of the modified model, Venkatesh \& Davis have been significantly expanded for TAM proposed extension of the technology acceptance model ${ }^{[4]}$, they introduce two new concepts as perceived usefulness of determinants: social processes influence and cognitive instrumental process. In addition, in 2003, Venkatesh again supplemented and amended technology acceptance model, proposed Unified Theory of Acceptance and Use of Technology (UTAUT) in reference to the theory of reasoned action (TRA), technology acceptance model (TAM), motivational model (MM), theory of planned behavior (TPB), Combined TAM and TPB model, model of PC utilization (MPCU) and innovation diffusion theory (IDT), social cognitive theory (SCT) and others.

TAM model has a lot of research literature and empirical support for MOOCs platform influencing factors with strong applicability, such as TAM early researches for e-commerce, information systems (Legris et al., 2003) ${ }^{[5]}$ in recent years, Moon \& Kim (2009) ${ }^{[6]}$ conducted a study on the applicability of TAM Web2.0 information systems. Compared with TAM, TRA and TPB models, we can see TAM is more representative, operable. The selection of the three strong related factors to form TAM integrated model has more practical value in use, the model variables, indicators have more understanding and interpretation, its applicability has been confirmed positively.

Task Fit Technology (TTF) theory comes from a theoretical model of information systems success model, the technical effect chain model. Goodhue and Thompson (1995) ${ }^{[7]}$ studied the relationship between early information platform and user behavior between individuals, considered that the consistency of task characteristics and technical characteristics affect the utilization efficiency of the source platform and relationships, which made the molding of the initial model. Through the improvement and expansion, technical characteristics and personal characteristics affect the common task of technical adaptation, and thus affect the results of the platform.

Compared with TTF, TAM focus on user' acceptance belief and attitude, TTF model focus more on the needs of the user's task, and the task of matching last task completion efficiency and use of resources, a combination of both final users a comprehensive view use willingness and motivation to continue to use. TTF blend in the personal characteristics, technical characteristics and task characteristics, to a certain extent, explain the modest impact of technology for MOOCs platform and personal characteristics affect the practical application and the results, providing a positive and effective support for MOOCs main factors.

TAM and TTF from the perspective of users, tasks, requirements, technology, and cognitive on the full range of comprehensive research study, which can be carried out multi-angle analysis of the study. Integration of these two models, users can fully explore MOOCs platform acceptance, use and process of the main factors, this study gives a more realistic background, in line with the actual study of a variety of conditions.

\section{Research Test bed}

Data collection used to test the research model obtained from learners online and offline. The questionnaire was designed to be placed as Web-based survey on the Public Website. Web-based surveys have been used in previous studies. The link to the online survey was sent by e-mail to who at least took one MOOCs course. The measures used in this article were mainly adapted from relevant prior studies: Based on the study of the background to fully understand, access to a large number of documents, designing the questionnaire format. The reliability and validity of the measurement instrument was evaluated using reliability and convergent validity criteria.

\section{System Evaluation}

Theoretical Model. Based on the theory of the two mature model by analyzing, selecting, removing and extending, to integrate it as a platform as to better explain MOOC user participation factors of the theoretical model. According to characteristics and user participation based on theoretical studies and 
MOOCs factors, build the following conceptual model in Fig 1, then come to assume this study, verified by methods such as structural equation.

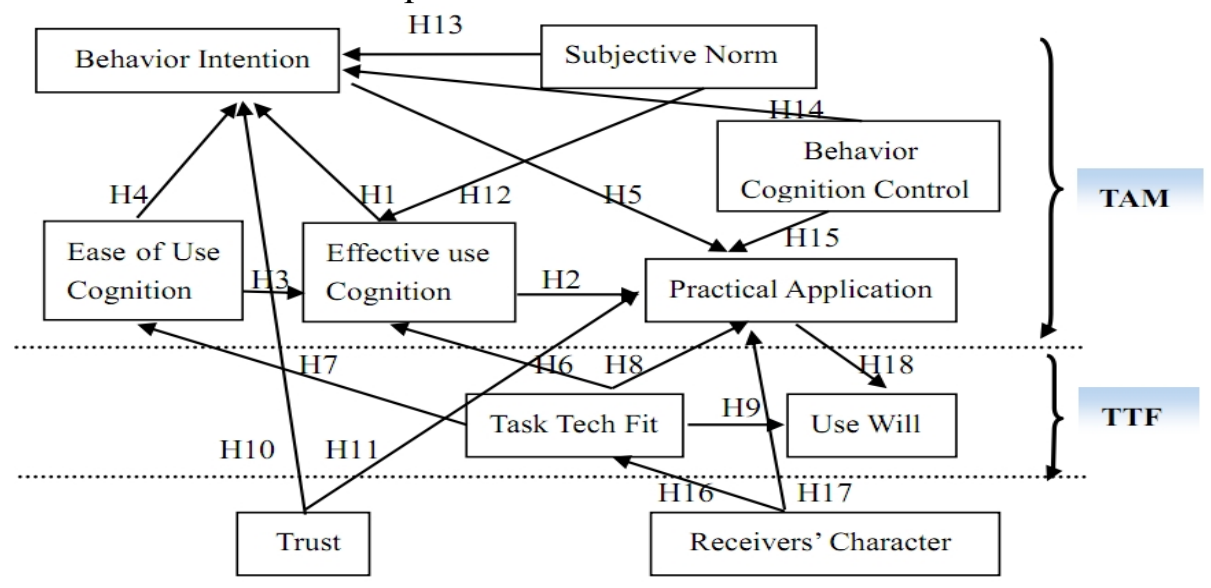

Figure 1 Conceptual Model

Research Hypothesis. According to Davis' view ${ }^{[8]}$, the users' perceived usefulness and user behavior will have a direct impact on the practical application, in other words, in order to learn a professional knowledge, even if the user does not like this platform, but if it can help him find the resources which he needed, and the price paid is relatively small, the user will choose to use this platform to carry out a course of study. Accordingly, we propose the following hypothesis:

H1 MOOCs perceived usefulness will positively affect the user' behavior intention of the platform.

H2 MOOCs perceived usefulness will positively affect user' practical application of the platform.

H3 MOOCs perceived ease of use will positively affect the user's perception of the usefulness of the platform.

H4 MOOCs perceived ease of use will positively affect the user' behavior intention of the platform.

H5 MOOCs behavioral intentions will positively affect the user's practical application of the platform.

H6 Users' demand for MOOCs matching will positively affect users' effective cognition of the platform.

H7 Users' demand for MOOCs matching will positively affect users' ease of use cognition of the platform.

H8 Users' demand for MOOCs matching will positively affect the users' practical application of the platform.

H9 Users' demand for MOOCs matching will positively affect the users' will to use the platform.

H10 Users' trust for MOOCs will positively affect the user' behavior intention of the platform.

H11 Users' trust for MOOCs will positively affect the users' practical application of the platform.

H12 Users' subjective norm for MOOCs will positively affect users' effective cognition of the platform.

H13 Users' subjective norm for MOOCs will positively affect the user' behavior intention of the platform.

H14 Users' cognitive behavioral control for MOOCs will positively affect the users' behavioral intentions of the platform.

H15 Users' cognitive behavioral control for MOOCs will positively affect the users' practical application of the platform.

H16 Users' features and characteristics of the recipient will positively affect matching the needs of the users.

H17 Users' features and characteristics of the recipient will positively affect the users' practical application of the platform. 
Platform only to be accepted and used so that the value of platform resources can be reflected, the actual behavior of their use is a direct impact on the use of the will, it is proposed:

H18 Users' practical application for MOOCs will positively affect the users' will to use the platform.

\section{Conclusions and Future Directions}

The advent of the era of big data to promote the development of a knowledge-based society. MOOCs Unlike traditional network and general education, the learning platform has strong autonomy, interaction and feedback, research-user factors can contribute to the improvement of the platform, while increasing the effectiveness of the user to use the platform.

In the future, we will put the questionnaires online and offline to collect much more valuable data for later analysis. In the process of determining the index of the conceptual model, mainly in TAM and TTF model based on user needs, satisfaction for the purpose of finding factors and verify correlation. According to users' main factors for MOOCs utility and the establishment of their relationships, combined with the successful experience at home and abroad, put forward practical proposals of building a better platform.

\section{References}

[1] Pappano L. The Year of the MOOC[J]. The New York Times, 2012, 2(12): 2012.

[2] El Kop S I, Sara H, Tabaa Y, et al. Massive Open Online Courses: A New Dawn for Higher Education [J]. International Journal on Computer Science and Engineering, 2013, 5(5): 323-327.

[3] Liqing, Wangtao. MOOC based on connectivism huge open courses mode [J][J]. China Distance Education, 2012, 3: 30-36.

[4] Venkatesh V, Morris M G, Davis G B, et al. User acceptance of information technology: Toward a unified view[J]. MIS quarterly, 2003: 425-478.

[5] Legris P, Ingham J, Collerette P. Why do people use information technology? A critical review of the technology acceptance model[J]. Information \& management, 2003, 40(3): 191-204.

[6] Moon J W, Kim Y G. Extending the TAM for a World-Wide-Web context[J]. Information \& Management, 2001, 38(4): 217-230.

[7] Goodhue D L, Thompson R L. Task-technology fit and individual performance[J]. MIS quarterly, 1995: 213-236.

[8] Venkatesh V, Morris M G, Davis G B, et al. User acceptance of information technology: Toward a unified view[J]. MIS quarterly, 2003: 425-478.

[9] Dishaw M T, Strong D M. Extending the technology acceptance model with task-technology fit constructs[J]. Information \& Management, 1999, 36(1): 9-21.

[10] McKnight H, Chervancy N L. An extended trust building model: Comparing experiential and non-experiential factors[J]. 2000.

[11] Ajzen I. The theory of planned behavior[J]. Organizational behavior and human decision processes, 1991, 50(2): 179-211.

[12] Miller D, Roger P H. Innovation in conservative and entrepreneurial firms: two models of strategic momentum[J]. Strategic management journal, 1982, 3(1): 1-25. 